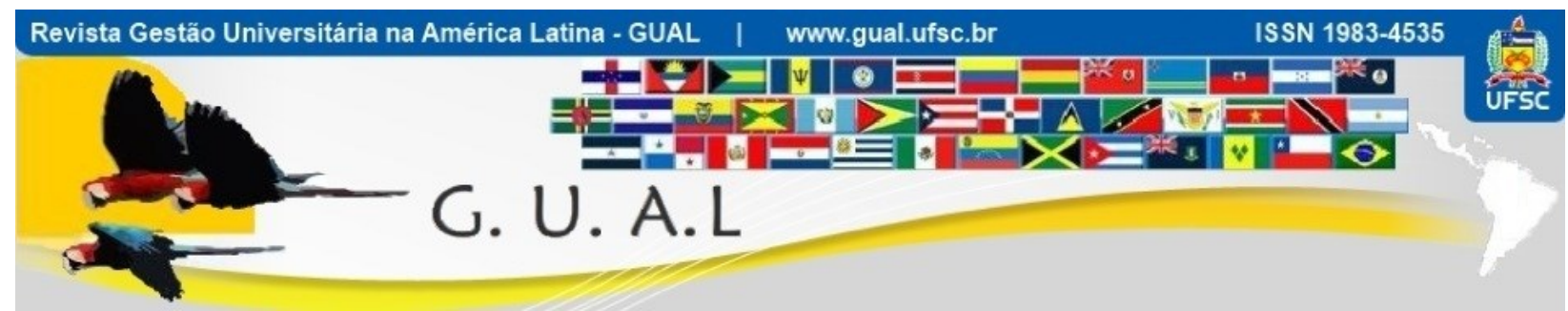

DOI: http://dx.doi.org/10.5007/1983-4535.2018v11n4p167

\title{
ESTRATÉGIAS E TÉCNICAS DE ENSINO- APRENDIZAGEM NO CURSO DE CIÊNCIAS CONTÁBEIS DA UNIVERSIDADE FEDERAL DE RONDÔNIA, CAMPUS DE PORTO VELHO: PERCEPÇÃO DOS GRADUANDOS
}

\section{TEACHING-LEARNING STRATEGIES AND TECHNIQUES IN THE ACCOUNTING COURSE OF FEDERAL UNIVERSITY OF RONDONIA, PORTO VELHO CAMPUS: STUDENTS' PERCEPTION}

\author{
Aline Fagundes de Melo, Graduada \\ Universidade Federal de Rondônia - UNIR \\ alinefmelo@outlook.com \\ Raísa Gabrielle Marques de Souza, Graduada \\ Universidade Federal de Rondônia - UNIR \\ raisa_gabrielle11@hotmail.com \\ Juocerlee Tavares Guadalupe Pereira de Lima, Doutorando \\ Universidade Federal de Rondônia - UNIR \\ juocerlee@unir.br \\ Gilberto Aparecido dos Santos, Mestrando \\ Universidade Federal de Rondônia - UNIR \\ gilberto.santos@unir.br
}

Recebido em 24/novembro/2017

Aprovado em 06/setembro/2018

Sistema de Avaliação: Double Blind Review

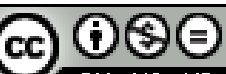

Esta obra está sob uma Licença Creative Commons Atribuição-Uso. 


\title{
ESTRATÉGIAS E TÉCNICAS DE ENSINO-APRENDIZAGEM NO CURSO DE CIÊNCIAS CONTÁBEIS DA UNIVERSIDADE FEDERAL DE RONDÔNIA, CAMPUS DE PORTO VELHO: PERCEPÇÃO DOS GRADUANDOS \\ DOI: http://dx.doi.org/10.5007/1983-4535.2018v11n4p167
}

\section{RESUMO}

A presente pesquisa objetivou verificar quais as principais estratégias e técnicas de ensinoaprendizagem utilizadas na educação contábil e que proporcionam maior eficácia ao aprendizado, na percepção dos alunos do curso de Ciências Contábeis. A pesquisa se caracteriza quanto ao objetivo como descritiva, quanto à abordagem de problema como qualiquatitativa, quanto aos procedimentos realizou-se pesquisa bibliográfica e levantamento de dados com aplicação de questionário. A pesquisa foi realizada na Universidade Federal de Rondônia - UNIR-localizada no Campus José Ribeiro Filho em Porto Velho. Foi considerado sujeito da pesquisa os alunos dos cursos de Ciências Contábeis. Através da análise de frequência e Ranking Médio os resultados mostram que as estratégias que geram maior eficácia para o aprendizado são: Aula Expositiva, Leitura/Estudo Dirigido, Trabalho em Grupo/Seminário, Discussão/ Debates/Grupos de oposição, Aulas com vídeo, Método do caso/estudo de caso, Aula pratica e de Laboratório e Aprendizagem experimental/ Estágio. Tais resultados foram convergentes com os estudos abordados no contexto do trabalho.

Palavras-chave: Estratégias. Processo de Ensino-Aprendizagem. Educação Contábil.

\begin{abstract}
The present study aimed to verify the main strategies and techniques of teaching and learning used in accounting education that provide greater efficacy to the learning, in accounting students' perception. The research is characterized as descriptive, which followed a qualitative-quantitative approach. Regarding the procedures, we carried out bibliographic research and data collection with questionnaire application. The research was carried out at the Federal University of Rondônia - UNIR-located at José Ribeiro Filho Campus in Porto Velho. The accounting students were considered as subjects of the research. Through the analysis of frequency and the average Ranking, the results show that the strategies that generate the most efficacy for learning are: Lecture, Reading / Directed Study, Group Work / Seminar, Discussion / Debates / Opposition groups, Video classes, Method of the case / case study, Practical and Laboratory Lecture and Experimental Learning / Internship. These results were convergent with the previous studies.
\end{abstract}

Keywords: Strategies. Teaching-Learning Process. Accounting Education 


\section{ESTRATÉGIAS E TÉCNICAS DE ENSINO-APRENDIZAGEM NO CURSO DE CIÊNCIAS CONTÁBEIS DA UNIVERSIDADE FEDERAL DE RONDÔNIA, CAMPUS DE PORTO VELHO: PERCEPÇÃO DOS \\ DOI: http://dx.doi.org/10.5007/1983-4535.2018v11n4p167}

\section{INTRODUÇÃO}

No cenário atual, estruturado a partir das constantes incertezas e rápidas mudanças, observa-se que as Instituições de Ensino Superior (IES) que são responsáveis pela formação dos profissionais, precisam estar atentas ao processo de ensino e aprendizagem, para garantir a qualidade da educação superior e a formação de profissionais capacitados para o exercício da profissão e comprometidos com o desenvolvimento da sociedade (SILVA; MELO, 2010; GARCIA; TORRES, 2016), uma vez que o ambiente competitivo faz com que o mercado de trabalho passe a requerer profissionais qualificados.

De acordo com Cittadin e Laesker (2010), nos cursos de Ciências Contábeis esta situação não é diferente, uma vez que o contador tem conquistado um papel de destaque na gestão das organizações. Diante deste contexto, ressalta-se que as práticas pedagógicas devem ser aprimoradas, visando proporcionar o desenvolvimento de uma série de competências inerentes à área contábil e afins.

No intuito de aprimorar suas teorias e práticas as IESs têm investido na reconstrução das estratégias de ensino, passando a ser uma preocupação mais transparente por parte dos sujeitos interessados no desenvolvimento da educação, criação e aplicação de novas metodologias de ensino que diretamente contribuam para melhoria efetiva do processo de aprendizagem. Segundo Costa, Pfeuti e Nova (2014), a busca de estratégias de ensinoaprendizagem (ou modalidades didáticas) são recursos utilizados no cotidiano da IESs, para assegurar aos estudantes alternativas que auxiliem atingir seus objetivos de aprendizagem. Dessa forma, cabe essas instituições a tarefa de decidir de que maneira o conhecimento pretendido chegará ao aluno, enfatizando mecanismos de dependência ou de independência em relação à figura do professor. Para Nossa (1999), a melhoria na qualidade de ensino não depende somente das mudanças curriculares e estruturais das Instituições de Ensino Superior, mas, principalmente, da seriedade, dedicação e compromisso assumido pelos professores na capacidade de formar bons profissionais e não apenas informá-los sobre alguns conteúdos.

Para Mazzioni (2013) e Leal e Borges (2016), o domínio exclusivo das estratégias de ensino não é suficiente para enfrentar todas as situações que ocorrem no processo de ensino e aprendizagem. Nesse sentido, os autores relatam que vários estudiosos apontam a relevância dos conhecimentos didáticos e apresentam as principais estratégias de ensino apontadas com maior frequência pelos estudiosos na área educacional (BORDENAVE; PEREIRA, 2002; 


\section{ESTRATÉGIAS E TÉCNICAS DE ENSINO-APRENDIZAGEM NO CURSO DE CIÊNCIAS CONTÁBEIS DA UNIVERSIDADE FEDERAL DE RONDÔNIA, CAMPUS DE PORTO VELHO: PERCEPÇÃO DOS GRADUANDOS \\ DOI: http://dx.doi.org/10.5007/1983-4535.2018v11n4p167}

LOPES et al., 2003; MASETTO, 2003; ANASTASIOU; ALVES, 2004; VIEIRA; VIEIRA, 2005; GIL, 2006; PILLETI, 2006; RANGEL, 2008;).

Para esses autores, ao aplicar as estratégias de ensino apresentadas, é importante verificar o objetivo de cada uma delas para o processo de aprendizagem do respectivo conteúdo. No caso específico de ciências contábeis, Boyce (2004) argumento que o processo de ensino-aprendizagem ainda tem a visão tradicional e se manifesta em uma abordagem que se baseia em técnicas de ensino passivo e se concentra na transferência de um corpo discreto de conhecimento processual, incluindo um conteúdo técnico-regulatório cada vez maior. Nesse sentido, considera-se que no ensino de contabilidade as estratégias utilizadas devem proporcionar aos alunos o desenvolvimento de habilidades e competências exigidas pelo mercado de trabalho.

Assim, o papel do docente torna-se cada vez mais importante para a educação contábil, principalmente, no que se refere à escolha dos métodos de ensino aplicados em sala de aula que podem ou não serem facilitadores no processo educacional. Deste modo, avaliar frequentemente a metodologia empregada e optar pela mais adequada, a determinada disciplina, possibilita o aprimoramento e enriquecimento do conteúdo proposto, sendo necessário, que as estratégias sejam delineadas de acordo com o perfil dos alunos, os recursos disponíveis e os objetivos predefinidos.

Diante do exposto, o presente trabalho buscou responder ao seguinte questionamento: Quais são as principais estratégias e técnicas de ensino-aprendizagem utilizadas na educação contábil e que proporcionam maior eficácia ao aprendizado, na percepção dos alunos do curso de Ciências Contábeis? Assim, para se atender a questão de pesquisa, propôs-se o seguinte objetivo geral: verificar as principais estratégias e técnicas de ensino-aprendizagem utilizadas na educação contábil e que proporcionam maior eficácia ao aprendizado, na percepção dos alunos do curso de Ciências Contábeis na Universidade Federal de Rondônia - UNIR.

O estudo se justifica pela relevância em identificar as estratégias e técnicas de ensino apontadas pelos discentes como mais eficazes para a educação contábil, o que poderá contribuir para a discussão sobre a temática e principalmente, proporcionar aos gestores acadêmicos possibilidades de análise sobre as estratégias e técnicas de ensino utilizadas. $\mathrm{O}$ resultado poderá contribuir ainda para a busca da qualidade do ensino superior de contabilidade evidenciando problemas que tangem a sua atual situação e comparando-os com literatura já existente sobre o tema em questão. Além disso, tem-se uma contribuição para a 


\section{ESTRATÉGIAS E TÉCNICAS DE ENSINO-APRENDIZAGEM NO CURSO DE CIÊNCIAS CONTÁBEIS DA UNIVERSIDADE FEDERAL DE RONDÔNIA, CAMPUS DE PORTO VELHO: PERCEPÇÃO DOS GRADUANDOS \\ DOI: http://dx.doi.org/10.5007/1983-4535.2018v11n4p167}

epistemologia do conhecimento na área, que poderá influenciar pesquisadores e professores a produzirem mais pesquisas sobre essa temática e refletirem sobre as estratégias e técnicas de ensino-aprendizagem por eles adotadas, tendo em vista uma abordagem de estudo desejada para os alunos.

Esta pesquisa está estruturada em cinco seções iniciando está introdução. A segunda seção apresenta a fundamentação teórica, em que são apresentadas as teorias de aprendizagem, uma abordagem sobre o processo de ensino-aprendizagem e as estratégias e técnicas de ensino-aprendizagem, em seguida apresenta alguns estudos anteriores que relatam os resultados encontrados referentes ao assunto pesquisado. A terceira seção apresenta o método e os procedimentos da pesquisa. A quarta seção traz os resultados da pesquisa. $\mathrm{Na}$ quinta seção, apresentam-se as conclusões da pesquisa.

\section{REFERENCIAL TEÓRICO}

\subsection{TEORIAS DE APRENDIZAGEM}

O processo de educação tem passado por transformações, que permite descobertas que contribuem para o desenvolvimento do processo de ensino-aprendizagem. Assim haverá não somente os aspectos técnicos que são considerados elementos básicos ao estudo da didática aplicada em sala de aula. O processo de ensino e aprendizagem depende de dois indivíduos que se relacionam entre si, um para ensinar e outro para aprender, sendo respectivamente o professor e o aluno. Esses dois atores fazem parte do processo pedagógico, no qual a aprendizagem por parte do aluno é o resultado do trabalho e o esforço do professor, que para ensinar é necessário estar preparado, tanto com o conhecimento a ser administrado como ter diferentes estratégias e técnicas para que isso ocorra. Segundo Lima, Kroenke e Hein (2010), a partir do momento em que o professor detecta dificuldades no aprendizado por parte do aluno, o mesmo articula caminhos com técnicas de aprendizagem para aplicar em sala de aula e facilitar o processo.

De acordo com Lima, Kroenke e Hein (2010), as teorias de aprendizagem fazem parte do direcionamento dos professores, para uma determinada área, na qual são elaboradas técnicas e sistemas de formas individuais, particulares, para resolver problemas ou tirar dúvidas. Os docentes necessitam buscar teorias de aprendizagem como modelos de ensino 


\section{ESTRATÉGIAS E TÉCNICAS DE ENSINO-APRENDIZAGEM NO CURSO DE CIÊNCIAS CONTÁBEIS DA UNIVERSIDADE FEDERAL DE RONDÔNIA, CAMPUS DE PORTO VELHO: PERCEPÇÃO DOS GRADUANDOS \\ DOI: http://dx.doi.org/10.5007/1983-4535.2018v11n4p167}

para estimular os alunos a aprenderem. Essas teorias muitas vezes são criadas para fazer com que o aluno aprenda.

Para Staub (2004 apud LIMA; KROENKE; HEIN, 2010), o conceito de aprendizagem inclui vários significados e algumas definições como o condicionamento, que está relacionada às modificações que acontecem ao aluno após o aprendizado, também está relacionada aos estímulos para resolver problemas, esse processo favorece o crescimento, amadurecimento na aprendizagem, explorando também novos significados e estruturas cognitivas.

Assim, a literatura tem apontado cinco (5) principais abordagens teóricas de renomados filósofos da educação, sobre a temática ensino-aprendizagem, como a Teoria Comportamentalista, a Teoria Humanista, a Teoria Construtivista e a Teoria sociocultural (LIMA; KROENKE; HEIN, 2010; OSTERMANN; CAVALCANTI, 2011).

Conforme Ostermann e Cavalcanti (2011), o criador do Behaviorismo metodológico chamado de Comportamentalismo é John B. Watson (1878-1958), possuindo como principal teórico Skinner, o objetivo Skinneriano é o estudo científico do comportamento. Para Lima e Kroenke e Hein (2010), revelam que através do comportamento cotidiano o aluno recebe estímulo para que tenha mudanças por meio do aprendizado e que essas experiências provocam mudanças no comportamento já existente.

Ainda sob o ponto de vista de Ostermann e Cavalcanti (2011), a teoria Humanista pertencente a Carl Rogers (1902-1987), sustenta que o aluno deve ser tratado como ser humano, com sentimentos, emoções e que tenha objetivos para o futuro, não apenas com comportamento e capacidade cognitiva, esta abordagem defende que a figura do professor deve ser real, ou seja, deve agir com sinceridade criando uma relação firme e segura, isso faz com que o aluno esteja seguro que não irá ser cobrado ou avaliado, desse modo supõe-se que o discente será criativo e autoconfiante.

A abordagem Construtivista está relacionada com assimilação mental, que se desenvolve quando o aluno busca construir uma ideia que o ajude na pratica da realidade, através do pensamento a ação se constrói, tendo como principal autor Jean Piaget (18961980), de acordo com Ostermann e Cavalcanti (2011), só acontece aprendizagem quando o esquema de assimilação sofre acomodação, quando a assimilação gera experiências, forças e novos pensamentos para sair da acomodação.

$\mathrm{Na}$ abordagem sociocultural, destacando-se Lima, Kroenke e Hein (2010), o aluno e o professor são transformados em sujeitos do processo educacional, ou seja, o conhecimento 


\section{ESTRATÉGIAS E TÉCNICAS DE ENSINO-APRENDIZAGEM NO CURSO DE CIÊNCIAS CONTÁBEIS DA UNIVERSIDADE FEDERAL DE RONDÔNIA, CAMPUS DE PORTO VELHO: PERCEPÇÃO DOS GRADUANDOS \\ DOI: http://dx.doi.org/10.5007/1983-4535.2018v11n4p167}

transmitido pelo professor vai ajudar o educando e o conhecimento do discente colabora com o do docente, que esse processo se realiza de forma reciproca. O teórico responsável é Paulo Freire (1921-1997), que defende que o aluno já vem com certa bagagem de conhecimento da mesma maneira que o professor. Essa troca de experiência transforma a realidade e se reflete na sociedade (OSTERMANN; CAVALCANTI, 2011).

\subsection{PROCESSO DE ENSINO-APRENDIZAGEM}

Para Itoz e Mineiro (2005), a didática é um conjunto de conhecimentos técnicos usados na transmissão de conteúdo. Entretanto, esse conceito tem mudado para o questionamento, no qual proporciona a reflexão, a crítica. É um dos elementos que influenciam o processo de ensino aprendizagem no qual o professor deve estar preparado para o tipo de aluno, da cultura que vai encontrar, e aplicar dinâmica. Portanto o professor deve se planejar, se perguntando: o que vou fazer? Para quem vou fazer? E como vou fazer para que o discente aprenda e transmita o que aprendeu?

Costa, Pfeuti e Nova (2014) corroboram com Itoz e Mineiro (2005), argumentando que a didática significa buscar caminhos para os problemas das práticas pedagógicas. Essa busca resulta nas teorias de ensino aprendizagem que são técnicas utilizadas pelos professores em sala de aula.

A contextualização abstrata segundo Costa, Pfeuti e Nova (2014), junta prática a teoria fazendo com que o aluno aplique seu conhecimento na vida real, e que o método voltado às aulas práticas possibilitam ao aluno enfrentar problemas, estimular o raciocínio e a imaginação, para chegar às soluções. A aprendizagem ativa relaciona o conhecimento à prática, por meio de encorajar o aluno a escrever e tomar nota de tudo que foi exposto em sala, por meio de matérias visuais, e a utilização das tecnologias, jogos, simulações de problemas e estudos coorporativos. Destacam-se também as aprendizagens voltadas aos alunos do Ensino Superior, como aula expositiva, estudo de casos, discussões em grupos, entre outras. O professor que determina como vai ministrar as aulas e qual método irá utilizar, ao utilizar as novas tecnologias nas aulas de contabilidade os professores proporcionam aos alunos habilidade de análise, de tomadas de decisões, e também nas comunicações, que são pouco usuais na disciplina de contabilidade.

Para Luckesi (1994), existem quatro tipos de abordagens de aprendizado segundo a tipologia de Convington, as quais se referem aos tipos de alunos: 


\section{ESTRATÉGIAS E TÉCNICAS DE ENSINO-APRENDIZAGEM NO CURSO DE CIÊNCIAS CONTÁBEIS DA UNIVERSIDADE FEDERAL DE RONDÔNIA, CAMPUS DE PORTO VELHO: PERCEPÇÃO DOS GRADUANDOS \\ DOI: http://dx.doi.org/10.5007/1983-4535.2018v11n4p167}

a) Super esforçados. São alunos autoconfiantes, bons estudantes, muito ansiosos e eles estudam muito tempo;

b) Orientados para o Sucesso. São autoconfiantes e bons, têm baixa ansiedade e um tempo médio de estudo;

c) Evitam o Fracasso. São os que têm dúvidas, sobre si mesmos, um pouco de dificuldade para estudar, ansiedade alta e utilizam pouco tempo para o estudo; e

d) Aceitam o Fracasso. Os alunos têm dúvidas sobre sua capacidade, um pouco de dificuldade de compreensão, ansiedade baixa e utilizam pouco tempo para estudar.

\subsection{ESTRATÉGIAS E TÉCNICAS DE ENSINO-APRENDIZAGEM}

A palavra estratégia segundo Mazzioni (2013) esteve ligada as artes da guerra, pois um bom exército deveria ter planejamento das ações de como combater seus inimigos, estratégias de sair à frente nas guerras.

Atualmente está relacionada ao ambiente empresarial e também entrou nas Universidades por meio das estratégias de Ensino Aprendizagem, hoje um bom docente deve possuir estratégias de ensino, saber administrar uma aula para que os discentes aprendam, devem proporcionar a curiosidade, a criatividade o interesse desses alunos pelo conteúdo administrado.

Luckesi (1994) argumenta que para se atingir os objetivos, as estratégias de ensino devem estar ligadas aos procedimentos de ensino, que são selecionados, construídos e mediados pelas propostas pedagógicas e metodológicas das Instituições de Ensino Superior. Para o procedimento ensino-aprendizagem vários fatores influenciam nos resultados esperados pelos professores, tais como as condições das estruturas da IES, as condições de trabalho dos docentes, as condições sociais dos alunos e os recursos disponíveis utilizados para administração das aulas.

Mazzioni (2013) esclarece que os objetivos que se pretende chegar, contam com as considerações e procedimentos de ensino aplicados aos educandos, esses procedimentos são escolhidos, analisados e considera também as habilidades necessárias para a execução da proposta pelo professor.

A seguir no Quadro 1 será apresentado um paralelo entre as estratégias de ensino proposto pela literatura de diferentes áreas e a proposta de ensino proposta na área da contabilidade (MAZZIONI, 2013; LEAL; BORGES, 2016). 


\section{ESTRATÉGIAS E TÉCNICAS DE ENSINO-APRENDIZAGEM NO CURSO DE CIÊNCIAS CONTÁBEIS DA UNIVERSIDADE FEDERAL DE RONDÔNIA, CAMPUS DE PORTO VELHO: PERCEPÇÃO DOS GRADUANDOS \\ DOI: http://dx.doi.org/10.5007/1983-4535.2018v11n4p167}

Quadro 1 Comparativo das Estratégias de Ensino.

\begin{tabular}{|c|c|}
\hline \multicolumn{2}{|c|}{ ESTRATÉGIAS DE ENSINO PROPOSTAS } \\
\hline (ANASTÁSIO; ALVES, 2004) & $\begin{array}{l}\text { (BORDENAVE; PEREIRA, 2002; LOPES et al., } \\
\text { 2003; MASETTO, 2003; PILLETI, 2006; GIL, } \\
\text { 2006; RANGEL, 2008; VIEIRA; VIEIRA, 2005) }\end{array}$ \\
\hline Estratégias de Ensino & Aprendizagem em Contabilidade \\
\hline Aula expositiva dialogada & Aula expositiva \\
\hline Estudo de texto & Leitura \\
\hline \multicolumn{2}{|l|}{ Portfólio } \\
\hline Tempestade cerebral & Discussão e Debate \\
\hline \multicolumn{2}{|l|}{ Mapa conceitual } \\
\hline Estudo dirigido & Estudo dirigido \\
\hline $\begin{array}{lccc}\begin{array}{l}\text { Lista de } \\
\text { informatizado }\end{array} & \text { discussão } & \text { por } & \text { meio } \\
\end{array}$ & Diálogos Sucessivos \\
\hline Soluções de problemas & Dinâmica de Grupo \\
\hline \multicolumn{2}{|l|}{ Philips 66} \\
\hline $\begin{array}{l}\text { Grupo de observação e verbalização. } \\
\text { GO/GV }\end{array}$ & Grupo de Verbalização e Observação. GO/GV \\
\hline Dramatização & Dramatização \\
\hline Seminários & Seminários \\
\hline Estudo de caso & Estudo de caso \\
\hline Júri simulado & Estágio \\
\hline Simpósio & Simpósio \\
\hline Painel & Painel Integrado \\
\hline \multicolumn{2}{|l|}{ Fórum } \\
\hline Oficina (laboratório ou workshop) & Aulas Práticas e de Laboratório \\
\hline Estudo de meio & Estudo de meio \\
\hline \multirow[t]{14}{*}{ Ensino com pesquisa } & Ensino com pesquisa \\
\hline & Debate em Sala de Aula \\
\hline & Ensino por Projetos \\
\hline & PBL (aprendizagem baseada em problema) \\
\hline & Formulação de Questões \\
\hline & Relato de Experiências \\
\hline & Aulas com Vídeo \\
\hline & Mesa Redonda \\
\hline & Instrução Programada \\
\hline & Ensino com Projeto \\
\hline & Jogos/Simulações \\
\hline & Visitas Técnicas e Excursões \\
\hline & Escritório, laboratório e empresa-modelo \\
\hline & Estudo de Texto \\
\hline
\end{tabular}

Fonte: Elaborado pelos autores, de acordo com Mazzioni (2013) e Leal e Borges (2016).

Considerando o paralelo das estratégias de ensino-aprendizagem elaboradas por Mazzioni (2013) e por Leal e Borges (2016), observa-se que as estratégias utilizadas pelos profissionais docentes na área da contabilidade não são diferentes, apenas em algumas nomenclaturas, mas são em quantidade maiores em relação as da área da pedagogia. Portanto, 


\section{ESTRATÉGIAS E TÉCNICAS DE ENSINO-APRENDIZAGEM NO CURSO DE CIÊNCIAS CONTÁBEIS DA UNIVERSIDADE FEDERAL DE RONDÔNIA, CAMPUS DE PORTO VELHO: PERCEPÇÃO DOS GRADUANDOS \\ DOI: http://dx.doi.org/10.5007/1983-4535.2018v11n4p167}

as estratégias devem partir do docente, com meios e técnicas para facilitar o ensinoaprendizagem.

Conforme Anastasiou e Alves (2004) o professor deverá ser um verdadeiro estrategista, ou seja, deverá estudar, selecionar, organizar e propor as melhores ferramentas facilitadoras para que os estudantes se apropriem do conhecimento. Leal e Borges (2016) corroboram com Anastasiou e Alves (2004), apresentado 12 (doze) estratégias de ensino, apresentadas a seguir no Quadro 2.

Quadro 2 Características das Estratégias de Ensino.

\begin{tabular}{|c|c|}
\hline ESTRATÉGIA & DESCRIÇÃO \\
\hline $\begin{array}{l}\text { Ensino com } \\
\text { Pesquisa }\end{array}$ & $\begin{array}{l}\text { Permite a iniciativa de informações; contato com diferentes fontes de informação; } \\
\text { selecionar, analisar e coletar dados e levantar informações para comprová-las; } \\
\text { fazer um relatório e pronunciar o seu resultado (MASETTO, 2003). }\end{array}$ \\
\hline $\begin{array}{l}\text { Ensino por } \\
\text { Projetos }\end{array}$ & $\begin{array}{l}\text { Tem como objetivo que o aluno "aprenda a propor o encaminhamento e } \\
\text { desenvolvimento de determinada situação [...] organizando um sistema de } \\
\text { acompanhamento de avaliação [...], de tal forma que a realização e integração das } \\
\text { várias etapas apresentem o projeto concluído" (MASETTO, 2003, p. 106). }\end{array}$ \\
\hline $\begin{array}{l}\text { Estudo de } \\
\text { Textos }\end{array}$ & $\begin{array}{l}\text { É a exploração de ideias de um autor a partir do estudo crítico de um texto e/ou a } \\
\text { busca de informações e exploração de ideias estudados (ANASTASIOU; ALVES, } \\
\text { 2003). }\end{array}$ \\
\hline Leitura & $\begin{array}{l}\text { O professor indica textos para a leitura, mas requer que esses textos sejam } \\
\text { didáticos e de poucas páginas para assim haver melhor compreensão e motivação } \\
\text { (MASETTO, 2003). }\end{array}$ \\
\hline $\begin{array}{l}\text { Estudo do } \\
\text { Meio }\end{array}$ & $\begin{array}{l}\text { É o ato de estudar sob a supervisão de um professor que possa sanar as dúvidas } \\
\text { que venham a surgir (ANASTASIOU; ALVES, 2003). }\end{array}$ \\
\hline Dramatização & $\begin{array}{l}\text { Requer que os alunos desenvolvam a empatia, a capacidade de desempenhar } \\
\text { papéis de outros e de analisar situações de conflito no ponto de vista de todos } \\
\text { envolvidos (MASETTO, 2003; ANASTASIOU; ALVES, 2003). }\end{array}$ \\
\hline $\begin{array}{l}\text { Dinâmica de } \\
\text { Grupo }\end{array}$ & $\begin{array}{l}\text { Desenvolve a capacidade de estudar em equipe, de discutir e debater, gerando } \\
\text { relatório dos resultados obtidos (MASETTO, 2003). }\end{array}$ \\
\hline $\begin{array}{l}\text { Visitas } \\
\text { Técnicas e } \\
\text { Excursões }\end{array}$ & $\begin{array}{l}\text { Feitas integradas com o conteúdo exposto em sala de aula, em que os alunos } \\
\text { observam e registram os dados coletados e emitem relatórios para discussão } \\
\text { (MASETTO, 2003). }\end{array}$ \\
\hline $\begin{array}{l}\text { Ensino em } \\
\text { Laboratório }\end{array}$ & $\begin{array}{l}\text { A aula em laboratório visa à eficiência na aprendizagem, atrelada com o conteúdo } \\
\text { já ministrado (MASETTO, 2003). }\end{array}$ \\
\hline Estágio & $\begin{array}{l}\text { Uma estratégia essencial para o aprendizado do aluno, o qual ele aplica na prática } \\
\text { profissional (MASETTO, 2003). }\end{array}$ \\
\hline Simpósio & $\begin{array}{l}\text { Desenvolvido mediante um tema proposto, de diferentes pontos de vista sobre o } \\
\text { assunto, por especialistas sobre o assunto, e, ao término da exposição, é aberta } \\
\text { para os participantes, com perguntas aos especialistas (RANGEL, 2008). }\end{array}$ \\
\hline Seminário & $\begin{array}{l}\text { Essa estratégia envolve a reunião de um grupo de pessoas para aprofundar em uma } \\
\text { determinação tema, com a orientação de uma ou várias pessoas (ANASTASIOU; } \\
\text { ALVES, 2003; VIEIRA; VIEIRA, 2005). }\end{array}$ \\
\hline
\end{tabular}

Fonte: Adaptado de Leal e Borges (2016). 


\section{ESTRATÉGIAS E TÉCNICAS DE ENSINO-APRENDIZAGEM NO CURSO DE CIÊNCIAS CONTÁBEIS DA UNIVERSIDADE FEDERAL DE RONDÔNIA, CAMPUS DE PORTO VELHO: PERCEPÇÃO DOS GRADUANDOS \\ DOI: http://dx.doi.org/10.5007/1983-4535.2018v11n4p167}

Pode-se observar no Quadro 2, inúmeras estratégias de ensino, de acordo com a literatura (MASETTO, 2003; ANASTASIOU; ALVES, 2003; VIEIRA; VIEIRA, 2005; RANGEL, 2008; LEAL; BORGES, 2016), entretanto, no ensino contábil, por se tratar de uma área vocacional, as estratégias de ensino devem se alinhar com a atenção diária dos alunos (BOYCE, 2004).

\subsection{ESTUDOS ANTERIORES SOBRE A TEMÁTICA}

Tem havido crescente preocupação acadêmica e científica, nacional e internacional sobre o processo de ensino-aprendizagem no curso de ciências contábeis, como pode-se observar através dos estudos de Mazzioni (2013), Nganga et al. (2013), Leal e Borges (2016) e Ferreira, Almeida e Araújo (2017).

Mazzioni (2013) objetivou compreender as estratégias de ensino mais significativas a partir da perspectiva dos alunos com aquelas utilizadas pelos professores de graduação em Ciência Contábeis no qual os resultados apontam uma harmonia entre as estratégias preferenciais dos discentes com a dos docentes, quais seja, a aula expositiva dialogada e a resolução de exercícios e seminários.

O objetivo do artigo de Nganga et al. (2013) foi identificar as estratégias de ensino utilizadas nos cursos de licenciatura de Pedagogia e Graduação em Ciências Contábeis no âmbito da Universidade Federal do Paraná e na Universidade Estadual de Maringá sob o ponto de vista dos discentes, em ambas instituições os resultados caracterizam-se por aulas expositivas e resolução de exercícios com dinâmicas de soluções de problemas e utilização de projetor multimídia.

O estudo Leal e Borges (2016), no qual o objetivo constitui-se em identificar sob a óptica dos discentes de graduação em Ciências Contábeis, as estratégias de ensino aplicadas na educação contábil na área de Contabilidade Gerencial e que gera maior eficácia ao aprendizado. Os resultados demonstram que os discentes consideram mais significativos os trabalhos realizados, a ser: Trabalhos em Grupo; Leituras/Estudos dirigidos e Aulas expositivas, tais resultados são convergentes com os estudos correlatos a respeito da temática em questão.

Ferreira, Almeida e Araújo (2017) demonstraram a percepção dos alunos do Curso Ciências Contábeis da Universidade Federal do Tocantins (UFT) sobre os métodos de ensino aplicados no curso. O resultado aponta que os métodos mais utilizados pelos professores são a 


\section{ESTRATÉGIAS E TÉCNICAS DE ENSINO-APRENDIZAGEM NO CURSO DE CIÊNCIAS CONTÁBEIS DA UNIVERSIDADE FEDERAL DE RONDÔNIA, CAMPUS DE PORTO VELHO: PERCEPÇÃO DOS GRADUANDOS \\ DOI: http://dx.doi.org/10.5007/1983-4535.2018v11n4p167}

aula expositiva e o trabalho em grupo, e os que mais contribuem e despertam interesse no processo de ensino aprendizagem são as aulas práticas/laboratório, debate, aula expositiva dialogada e trabalho em grupo.

\section{METODOLOGIA}

A presente pesquisa se caracteriza como descritiva. Segundo Gil (2008, p. 42), esse tipo de pesquisa "têm como objetivo primordial a descrição das características de determinada população ou fenômeno ou, então, o estabelecimento entre variáveis". Quanto aos procedimentos realizou-se, primeiramente, uma pesquisa bibliográfica, visto que este tipo de estudo procura explicar um problema a partir de referências teóricas publicadas em documentos. De acordo com Fonseca (2002, p.32) “a pesquisa bibliográfica é feita a partir do levantamento de referências teóricas já analisadas, e publicadas por meios escritos e eletrônicos, como livros, artigos científicos, páginas de web sites". Para a abordagem do problema foram aplicados tanto métodos qualitativos, como os quantitativos. Assim, seguindo a abordagem de Creswell (2009), a presente pesquisa é de abordagem quali-quantitativa, uma vez que se concentra na compreensão do problema utilizando concomitantemente, os dois métodos.

Em relação aos procedimentos técnicos, foi realizado levantamento (survey) de dados por meio da aplicação de um questionário. A partir da revisão da literatura e, principalmente, do levantamento de estudos anteriores, foram identificadas as principais estratégias de ensino, o que resultou na adaptação do instrumento de pesquisa utilizado no estudo de Miranda, Leal e Casa Nova (2012), Nganga et al. (2013) e Leal e Borges (2016) para a elaboração de um questionário. De acordo com Gil (2005, p. 128) “é a técnica de investigação composta por um número mais ou menos elevado de questões apresentadas por escrito a pessoas, tendo por objetivo o conhecimento de opiniões, crenças, sentimentos, interesses, expectativas, situações vivenciadas etc." O referido questionário foi constituído por perguntas abertas e fechadas, e algumas delas em escala Likert de 5 pontos. Assim o questionário foi dividido em quatro partes: (I) caracterização dos alunos (II) processo de ensino-aprendizagem (III) identificação das estratégias de ensino conhecidas, utilizadas e consideradas de maior eficácia no ensino da contabilidade; (IV) razões (motivos) e fatores que influenciam a escolha das estratégias de ensino. 


\section{ESTRATÉGIAS E TÉCNICAS DE ENSINO-APRENDIZAGEM NO CURSO DE CIÊNCIAS CONTÁBEIS DA UNIVERSIDADE FEDERAL DE RONDÔNIA, CAMPUS DE PORTO VELHO: PERCEPÇÃO DOS GRADUANDOS \\ DOI: http://dx.doi.org/10.5007/1983-4535.2018v11n4p167}

Na primeira parte do questionário se procurou fazer a caracterização dos alunos a partir das seguintes características: sexo; faixa etária; experiência ou não na área contábil; período que está cursando. Na segunda parte, tratou-se do processo de ensino-aprendizagem, mais precisamente sobre o que mais auxilia na assimilação do conteúdo das disciplinas e se a desatenção dos alunos está associada com o método utilizado pelo professor. Por outro lado, foram questionados sobre os recursos didáticos utilizados com maior frequência pelos professores. Na terceira parte do questionário se procurou identificar as técnicas de ensino conhecidas, utilizadas e consideradas de maior eficácia no ensino. Para a quarta parte do questionário, solicitou-se aos alunos, que na percepção dos mesmos, marcassem uma ou mais alternativas que justificam às razões quanto a escolha de estratégias que geram maior eficácia e quais fatores influenciam na decisão dos docentes na escolha das estratégias de ensino.

Para a análise dos dados utilizou-se a técnica de frequência (relativa e absoluta) para cada quesito avaliado. Por outro lado, utilizou-se a técnica de Ranking Médio (OLIVEIRA, 2005), para uma pergunta, cujo dados foram obtidos por meio da escala tipo Likert de 5 pontos. Para o cálculo do Ranking Médio (RM) utilizou-se as médias ponderadas obtidas através das respostas em escala Likert (1-5), para cada quesito analisado, de acordo com as seguintes fórmulas:

$$
M P=\sum(f i . V i)
$$

(1)

Sendo que:

MP $=$ Média Ponderada

$\mathrm{Fi}=$ Frequência observada de cada resposta para cada item

$\mathrm{Vi}=$ Valor de cada resposta

$R M=M P / n$

(2)

Sendo que:

RM = Ranking Médio

$\mathrm{n}=$ Número de respondentes

Após as análises os dados foram tabulados e plotados para maior análise e interpretação.

A pesquisa foi realizada na Universidade Federal de Rondônia - UNIR - localizada no Campus José Ribeiro Filho em Porto Velho, foi considerado sujeitos da pesquisa os alunos 


\section{ESTRATÉGIAS E TÉCNICAS DE ENSINO-APRENDIZAGEM NO CURSO DE CIÊNCIAS CONTÁBEIS DA UNIVERSIDADE FEDERAL DE RONDÔNIA, CAMPUS DE PORTO VELHO: PERCEPÇÃO DOS GRADUANDOS \\ DOI: http://dx.doi.org/10.5007/1983-4535.2018v11n4p167}

dos cursos de Ciências Contábeis. O questionário foi aplicado aos alunos regularmente matriculados no segundo semestre de 2016, neste semestre constam-se os períodos impares, cujo curso tem duração de 4 anos. A inclusão dos elementos na pesquisa se deu por acessibilidade, condicionada ao contato com os estudantes que estiveram presentes no dia em que se realizou a investigação. A coleta de dados ocorreu no mês de novembro/2016, nos dias 24,25 e 28 , tendo sido o questionário aplicado em sala de aula. Estima-se um total de150 alunos matriculados nos períodos, a estimativa de deu da seguinte forma, considerando que nem todos os alunos que egressa no mesmo período se formam juntos e todo início do segundo semestre entra na instituição 50 alunos e com base nas turmas anteriores estima-se que $30 \%$ desses alunos desistem logo no primeiro período. Portanto a amostra do estudo é composta de 73 alunos, o que corresponde a 48,67\% da população investigada.

\section{RESULTADOS}

Na primeira parte da análise dos dados, apresenta-se a caracterização dos alunos que participaram da pesquisa. A tabela 1 evidencia os resultados quanto ao sexo, idade, experiência no mercado e distribuição por período matriculado.

Tabela 1 Caracterização dos alunos

\begin{tabular}{|c|c|c|c|c|c|}
\hline Sexo & Frequência & $\%$ & Experiência contábil & Frequência & $\%$ \\
\hline Feminino & 27 & $36,99 \%$ & Sim & 41 & $56,16 \%$ \\
\hline Masculino & 46 & $63,01 \%$ & Não & 31 & $42,47 \%$ \\
\hline \multirow[t]{2}{*}{ Total } & 73 & $100 \%$ & Não respondeu & 1 & $1,37 \%$ \\
\hline & & & $\begin{array}{l}\text { Total } \\
\quad \text { Período no curso }\end{array}$ & 73 & $100 \%$ \\
\hline Até 20 anos & 14 & $19,18 \%$ & $1^{\mathrm{o}}$ período & 14 & $19,18 \%$ \\
\hline 21-30 anos & 43 & $58,90 \%$ & $3^{\circ}$ período & 18 & $24,66 \%$ \\
\hline $31-40$ anos & 10 & $13,70 \%$ & $5^{\circ}$ período & 13 & $17,81 \%$ \\
\hline 41-50 anos & 6 & $8,22 \%$ & $7^{\circ}$ período & 28 & $38,35 \%$ \\
\hline Mais & - & - & Total & 73 & $100 \%$ \\
\hline Total & 73 & $100 \%$ & & & \\
\hline
\end{tabular}

Fonte: Dados da pesquisa.

Verifica-se que 63,01\% dos respondentes são do gênero masculino. Quanto à idade de maior frequência, é o intervalo de 21 e 30 anos (58,90\%), e 56,16\% dos estudantes já possuem experiência na área contábil. Ressalta-se que o período que tem mais alunos é o $1^{\mathrm{o}}$ período, porém número de respondentes não foi como esperado, pois apenas 14 alunos se dispuseram a responder. 


\section{ESTRATÉGIAS E TÉCNICAS DE ENSINO-APRENDIZAGEM NO CURSO DE CIÊNCIAS CONTÁBEIS DA UNIVERSIDADE FEDERAL DE RONDÔNIA, CAMPUS DE PORTO VELHO: PERCEPÇÃO DOS GRADUANDOS \\ DOI: http://dx.doi.org/10.5007/1983-4535.2018v11n4p167}

Após o perfil dos respondentes, verificou-se sobre o processo de ensino-aprendizagem que mais auxilia na assimilação do conteúdo. Os resultados foram apresentados no Gráfico 1.

Gráfico 1 Processo de ensino-aprendizagem que mais auxilia na assimilação do conteúdo.

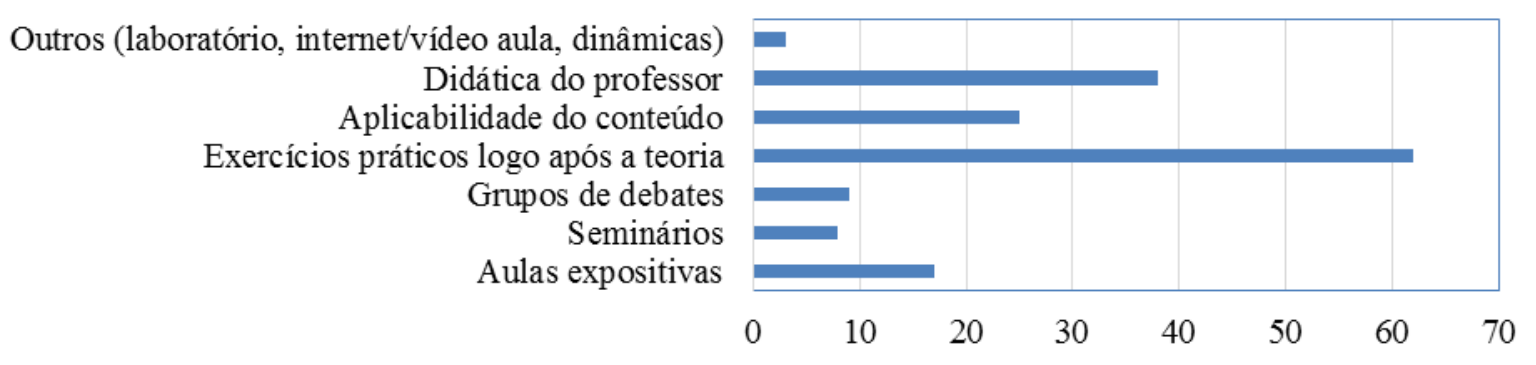

Fonte: Dados da pesquisa.

Nota-se no Gráfico 1 que quase a totalidade dos pesquisados indicaram mais de um processo de ensino em conjunto. Para os alunos o processo que mais auxilia na assimilação de conteúdo é os exercícios práticos, com 62 escolhas $(38,27 \%)$, logo após a teoria $(38,27 \%)$ em seguida a didática do professor $(23,46 \%)$. Na alternativa outras temos as opções laboratório, internet/vídeo aula, dinâmicas que correspondem (1,85\%). De acordo com Mazzioni (2013), a maneira pela qual o professor planeja suas atividades de sala de aula é determinante para que o grupo de alunos de sua plateia reaja com maior ou menor interesse e contribui no modo como a aula transcorre.

Questionou-se aos alunos se a desatenção dos mesmos está associada com o método utilizado pelo professor, nesta questão foi respondida somente uma alternativa, como se observa na Tabela 2, analisada através do Ranking Médio.

Tabela 2 Ranking Médio sobre a associação entre a desatenção dos alunos e o método utilizado pelo professor

\begin{tabular}{lcccccc}
\hline \multicolumn{1}{c}{ Dificuldades } & Ranking Médio & \multicolumn{5}{c}{ Grau de Concordância } \\
\cline { 2 - 7 } & $\mathbf{3}$ & $\mathbf{2}$ & $\mathbf{3}$ & $\mathbf{4}$ & $\mathbf{5}$ \\
\hline $\begin{array}{l}\text { Desatenção dos alunos está } \\
\text { associada com o método } \\
\text { utilizado pelo professor }\end{array}$ & $\mathbf{3}$ & $\mathbf{1 7}$ & $\mathbf{1}$ & $\mathbf{4 7}$ & $\mathbf{6}$ \\
\hline
\end{tabular}

Legenda: 1 Descordo Totalmente; 2: Discordo Parcialmente; 3 Neutro; 4: Concordo Parcialmente; e 5: Concordo Totalmente

Fonte: Dados da pesquisa 


\section{ESTRATÉGIAS E TÉCNICAS DE ENSINO-APRENDIZAGEM NO CURSO DE CIÊNCIAS CONTÁBEIS DA UNIVERSIDADE FEDERAL DE RONDÔNIA, CAMPUS DE PORTO VELHO: PERCEPÇÃO DOS GRADUANDOS \\ DOI: http://dx.doi.org/10.5007/1983-4535.2018v11n4p167}

O resultado na Tabela 2 ilustra que apesar da divisão das opiniões, maior parte dos alunos objeto da pesquisa consideram que a desatenção dos alunos está associada com o método utilizado pelo professor, com um Ranking Médio de 3,52. Esse resultado converge com a literatura (BOYCE, 2004; ITOZ; MINEIRO, 2005). São várias as estratégias de ensino que são utilizadas pelos educadores para ministrar os conteúdos, mas é necessário entender os significados de tais estratégias para, assim, direcionar o estudo. Dessa maneira, o método de ensino tem que proporcionar uma sinergia eficiente e eficaz do docente com o educando, promovendo melhores condições para o processo de ensino-aprendizagem.

A seguir será apresentado os recursos didáticos que são utilizados com maior frequência pelos professores no curso de Contabilidade, através da Tabela 3.

Tabela 3 Recursos didáticos

\begin{tabular}{|c|c|c|}
\hline Recursos didáticos utilizados & Frequência & $\%$ \\
\hline Data show & 63 & $35,20 \%$ \\
\hline Quadro branco & 49 & $27,37 \%$ \\
\hline Laboratório de informática & 1 & $0,57 \%$ \\
\hline Retroprojetor & 3 & $1,68 \%$ \\
\hline Apostilas & 27 & $15,08 \%$ \\
\hline Artigos & 20 & $11,17 \%$ \\
\hline Visitas às empresas & 4 & $2,23 \%$ \\
\hline Auditórios & - & - \\
\hline Trabalho extraclasse & 12 & $6,70 \%$ \\
\hline Total & & $100 \%$ \\
\hline
\end{tabular}

Fonte: Dados da pesquisa.

A definição do uso de determinada estratégia de ensino-aprendizagem considera os objetivos que o docente estabelece e as habilidades a serem desenvolvidas em cada série de conteúdo. A Tabela 3 demonstra a indicação por parte dos alunos de quais recursos didáticos são mais utilizados pelos professores da área contábil. Percebe-se que o recurso mais utilizado é o Data show, seguido do quadro branco o que ajuda a ressaltar o uso de exercícios práticos logo após a teoria citado na Tabela 3. O uso do laboratório de informática é o recurso que o professor usa com menor frequência.

A terceira parte do questionário consiste na identificação das técnicas de ensino conhecidas, utilizadas e consideradas de maior eficácia no ensino da contabilidade, como demonstra a Tabela 4. 


\section{ESTRATÉGIAS E TÉCNICAS DE ENSINO-APRENDIZAGEM NO CURSO DE CIÊNCIAS CONTÁBEIS DA UNIVERSIDADE FEDERAL DE RONDÔNIA, CAMPUS DE PORTO VELHO: PERCEPÇÃO DOS GRADUANDOS \\ DOI: http://dx.doi.org/10.5007/1983-4535.2018v11n4p167}

Tabela 4 Estratégias de ensino conhecida pelo aluno e utilizada pelo professor

\begin{tabular}{|c|c|c|c|c|}
\hline \multirow[b]{2}{*}{ Estratégias } & \multicolumn{2}{|c|}{ Conhecida pelo aluno } & \multicolumn{2}{|c|}{ Utilizada pelo professor } \\
\hline & Frequência & $\%$ & Frequência & $\%$ \\
\hline Aula expositiva & 59 & $8,59 \%$ & 57 & $12,97 \%$ \\
\hline Leitura/ Estudo dirigido & 58 & $8,44 \%$ & 45 & $10,25 \%$ \\
\hline $\begin{array}{l}\text { Discussão/ Debates/Grupos de } \\
\text { oposição }\end{array}$ & 56 & $8,15 \%$ & 47 & $10,71 \%$ \\
\hline Trabalhos em grupos/Seminário & 57 & $8,30 \%$ & 55 & $12,53 \%$ \\
\hline Estudo do meio & 15 & $2,18 \%$ & 9 & $2,05 \%$ \\
\hline Aula pratica e de Laboratório & 36 & $5,24 \%$ & 17 & $3,87 \%$ \\
\hline Aprendizagem experimental/ Estágio & 31 & $4,51 \%$ & 3 & $0,68 \%$ \\
\hline Visitas técnicas e Excursões & 28 & $4,08 \%$ & 11 & $2,51 \%$ \\
\hline Painel integrado & 11 & $1,60 \%$ & 4 & $0,91 \%$ \\
\hline Formulação de questões & 30 & $4,37 \%$ & 25 & $5,69 \%$ \\
\hline Método do caso/estudo de caso & 39 & $5,68 \%$ & 29 & $6,61 \%$ \\
\hline Relato de experiência & 19 & $2,77 \%$ & 21 & $4,78 \%$ \\
\hline Aulas com vídeo & 42 & $6,11 \%$ & 35 & $7,97 \%$ \\
\hline Mesa redonda & 20 & $2,91 \%$ & 6 & $1,37 \%$ \\
\hline Simpósio & 17 & $2,47 \%$ & 2 & $0,46 \%$ \\
\hline Dramatizações & 17 & $2,47 \%$ & 2 & $0,46 \%$ \\
\hline Instrução programada & 13 & $1,89 \%$ & 5 & $1,14 \%$ \\
\hline Ensino com projeto & 18 & $2,62 \%$ & 9 & $2,05 \%$ \\
\hline PBL (Ensino Baseado em Problemas) & 17 & $2,47 \%$ & 5 & $1,14 \%$ \\
\hline Jogos/ Simulações em laboratório & 28 & $4,08 \%$ & 10 & $2,28 \%$ \\
\hline Grupo de verbalização e observação & 16 & $2,33 \%$ & 5 & $1,14 \%$ \\
\hline Diálogos sucessivos & 22 & $3,20 \%$ & 11 & $2,51 \%$ \\
\hline Ensino com pesquisa & 31 & $4,51 \%$ & 21 & $4,78 \%$ \\
\hline Outros (não identificados) & 6 & $0,87 \%$ & 4 & $0,91 \%$ \\
\hline Outros (resenha) & 1 & $0,16 \%$ & 1 & $0,23 \%$ \\
\hline Total & & $100 \%$ & & $100 \%$ \\
\hline
\end{tabular}

Fonte: Dados da pesquisa.

Conforme exposto na Tabela 4, as estratégias mais conhecidas pelos alunos coincidem com aquelas utilizadas no ensino da educação contábil, sendo as maiores frequências para: Aula Expositiva, Leitura/Estudo Dirigido, Trabalho em Grupo/Seminário, Discussão/ Debates/Grupos de oposição, Aulas com vídeo e Método do caso/estudo de caso. Observa-se que as 6 estratégias mais conhecidas pelos alunos têm representatividades de $44.83 \%$. Sendo as mais utilizadas pelos professores 61,04\%. As estratégias de ensino com menor grau de conhecimento e menos utilizadas nas aulas referem-se a: resenhas, outros que não foram identificados pelos alunos, Instrução Programada, Dramatização, Painel Integrado e estudo do meio. Importante destacar, que a estratégia Aprendizagem experimental/ Estágio é conhecida pelos alunos $(4,51 \%)$, mas apenas $0,68 \%$ indicaram que essa estratégia é utilizada no ensino da educação contábil. 


\section{ESTRATÉGIAS E TÉCNICAS DE ENSINO-APRENDIZAGEM NO CURSO DE CIÊNCIAS CONTÁBEIS DA UNIVERSIDADE FEDERAL DE RONDÔNIA, CAMPUS DE PORTO VELHO: PERCEPÇÃO DOS GRADUANDOS \\ DOI: http://dx.doi.org/10.5007/1983-4535.2018v11n4p167}

Os estudantes foram questionados sobre quais as estratégias de ensino geram maior eficácia para o aprendizado na educação contábil. A Tabela 5 demonstra os números totais de estratégias escolhidas e a porcentagens de cada uma. Os resultados, conforme Tabela 5, evidenciam 22 estratégias escolhidas múltiplas vezes. A mais frequente foi a Aula expositiva, com uma frequência relativa de 12,86\%, seguida de Aula Prática e de Laboratório com $10,33 \%$ e Discussão/Debates/Grupos de oposição, com frequência relativa de 8,5\%. Destaque também para Aprendizagem Experimental/Estágio, com frequência relativa de 7,82\% e Leitura/ Estudo dirigido, com 7,36\%. Importa destacar que essas 6 (seis) estratégias, representam $46,87 \%$. Já as estratégias que geram menor eficácia para o aprendizado (menos de 10 escolhas) foram: Grupo de verbalização e observação, Dramatizações, Simpósio, Instrução Programada, Diálogos sucessivos, Mesa redonda e PBL. Todas essas estratégias representam $8,05 \%$ do total das escolhas. A única estratégia que não teve nenhuma escolha foi Painel integrado.

Tabela 5 Estratégias mais significativas para o ensino da educação contábil

\begin{tabular}{|c|c|c|}
\hline Estratégias mais significativas & Frequência & $\%$ \\
\hline Aula expositiva & 56 & $12,86 \%$ \\
\hline Leitura/ Estudo dirigido & 32 & $7,36 \%$ \\
\hline Discussão/ Debates/Grupos de oposição & 37 & $8,50 \%$ \\
\hline Trabalhos em grupos/Seminário & 31 & $7,13 \%$ \\
\hline Estudo do meio & 14 & $3,22 \%$ \\
\hline Aula pratica e de Laboratório & 45 & $10,33 \%$ \\
\hline Aprendizagem experimental/ Estágio & 34 & $7,82 \%$ \\
\hline Visitas técnicas e Excursões & 19 & $4,37 \%$ \\
\hline Formulação de questões & 18 & $4,14 \%$ \\
\hline Método do caso/estudo de caso & 26 & $5,98 \%$ \\
\hline Relato de experiência & 14 & $3,22 \%$ \\
\hline Aulas com vídeo & 23 & $5,29 \%$ \\
\hline Mesa redonda & 7 & $1,61 \%$ \\
\hline Simpósio & 4 & $0,92 \%$ \\
\hline Dramatizações & 4 & $0,92 \%$ \\
\hline Instrução programada & 5 & $1,15 \%$ \\
\hline Ensino com projeto & 15 & $3,45 \%$ \\
\hline PBL (Ensino Baseado em Problemas) & 7 & $1,61 \%$ \\
\hline Jogos/ Simulações em laboratório & 15 & $3,45 \%$ \\
\hline Grupo de verbalização e observação & 3 & $0,69 \%$ \\
\hline Diálogos sucessivos & 5 & $1,15 \%$ \\
\hline Ensino com pesquisa & 21 & $4,83 \%$ \\
\hline Total & 435 & $100 \%$ \\
\hline
\end{tabular}

Fonte: Dados da pesquisa. 


\section{ESTRATÉGIAS E TÉCNICAS DE ENSINO-APRENDIZAGEM NO CURSO DE CIÊNCIAS CONTÁBEIS DA UNIVERSIDADE FEDERAL DE RONDÔNIA, CAMPUS DE PORTO VELHO: PERCEPÇÃO DOS GRADUANDOS \\ DOI: http://dx.doi.org/10.5007/1983-4535.2018v11n4p167}

Tais resultados (TABELA 5) Nsão convergentes com os estudos de Miranda, Leal e Casa Nova (2012), Mazzioni (2013), Nganga et al. (2013), Leal e Borges (2016) e Ferreira, Almeida e Araújo (2017). Esses resultados sinalizam que as estratégias de ensino contábil devem ser mais interativas, ao ponto de haver uma participação ativa dos alunos no processo de ensino-aprendizagem.

Questionou-se aos participantes quais razões justificam a eficácia das estratégias de ensino utilizadas na educação contábil. Sendo marcada uma ou mais alternativas que estão apresentadas na Tabela 6 .

Tabela 6 Razões de escolha que justificam a eficácia das estratégias de ensino utilizada na educação contábil

\begin{tabular}{|c|c|c|}
\hline Razões que justificam a eficácia das estratégias de ensino & Frequência & $\%$ \\
\hline Facilita o aprendizado & 64 & $17,02 \%$ \\
\hline Auxilia na fixação do conteúdo & 46 & $12,23 \%$ \\
\hline Aproxima teoria a prática & 53 & $14,10 \%$ \\
\hline Motiva aprendizado & 40 & $10,64 \%$ \\
\hline Desperta o interesse & 47 & $12,50 \%$ \\
\hline Proporciona interação aluno/professor & 29 & $7,71 \%$ \\
\hline Possibilita troca de experiência & 29 & $7,71 \%$ \\
\hline São as técnicas mais usadas & 5 & $1,33 \%$ \\
\hline São dinâmicas & 28 & $7,45 \%$ \\
\hline Estimula a criatividade & 13 & $3,46 \%$ \\
\hline Estimula novas pesquisas & 22 & $5,85 \%$ \\
\hline Outros & - & - \\
\hline Total & 376 & $100 \%$ \\
\hline
\end{tabular}

Fonte: Dados da pesquisa.

Percebe-se através da Tabela 6 que as razões que os alunos consideram para a escolha das estratégias mais eficazes para o ensino da educação contábil são as que: facilitam o aprendizado, com $17,02 \%$ de frequência relativa, aproxima a teoria da prática, com $14,10 \%$, desperta o interesse com 12,50\%, auxilia na fixação do conteúdo, com 12,23\% e motiva aprendizado com 10,64\%. Importa salientar que essas 5 (cinco) alternativas representam cerca de $66 \%$ em relação ao total de escolhas. Também foram questionados aos estudantes quais fatores eles consideram que influenciam na escolha das estratégias de ensino pelo docente da área da educação contábil. A Tabela 7 apresenta os resultados encontrados. 
Tabela 7 Fatores de influência na escolha das estratégias de ensino.

\begin{tabular}{lcc}
\hline \multicolumn{1}{c}{ Fatores de influência na escolha das estratégias de ensino } & Frequência & $\%$ \\
\hline Experiência didática do professor & $\mathbf{5 3}$ & $\mathbf{3 0 , 6 4 \%}$ \\
Objetivos educacionais & $\mathbf{3 4}$ & $\mathbf{1 9 , 6 5 \%}$ \\
Tempo disponível & $\mathbf{2 8}$ & $\mathbf{1 6 , 1 8 \%}$ \\
Estrutura de assunto/ Tipo de aprendizado & $\mathbf{3 0}$ & $\mathbf{1 7 , 3 4 \%}$ \\
Condições físicas da sala & 15 & $8,67 \%$ \\
Tipos de alunos da sala & 12 & $6,94 \%$ \\
Outros (egocentrismo) & 1 & $0,58 \%$ \\
\hline Total & $\mathbf{1 7 3}$ & $\mathbf{1 0 0 \%}$ \\
\hline
\end{tabular}

Fonte: Dados da pesquisa.

Pode-se observar através dos resultados expostos na Tabela 7 que os alunos consideram que os principais fatores que influenciam na escolha das estratégias de ensino na educação contábil, pelos professores, são: experiência didática do professor, com frequência relativa de 30,64\%, os objetivos educacionais definidos pelos professores, com frequência relativa de 19,65\%, a estrutura do assunto/tipo de aprendizado, com frequência relativa de $17,34 \%$ e tempo disponível para a aula, com frequência relativa de $16,18 \%$. Os resultados encontrados são convergentes com as abordagens propostas por Luckesi (1994), e Mazzioni (2013).

No geral, o resultado do estudo converge com a literatura (LUCKESI, 1994; ITOZ; MINEIRO, 2005; MIRANDA; LEAL; CASA NOVA, 2012, MAZZIONI, 2013; NGANGA et al., 2013; LEAL; BORGES, 2016; FERREIRA; ALMEIDA; ARAÚJO, 2017).

\section{CONCLUSÃO}

A presente pesquisa objetivou verificar quais as principais estratégias e técnicas de ensino-aprendizagem utilizada na educação contábil e que proporcionam maior eficácia ao aprendizado, na percepção dos alunos do curso. O resultado aponta que o recurso mais utilizado é Data show, seguido quadro branco o que ajuda a ressaltar o uso de exercícios práticos logo após a teoria. Identificou-se ainda que as estratégias mais conhecidas coincidem com aquelas utilizadas no ensino da educação contábil pelos professores, e que geram maior eficácia para o aprendizado, sendo: Aula Expositiva, Leitura/Estudo Dirigido, Trabalho em Grupo/Seminário, Discussão/Debates/Grupos de oposição, Aulas com vídeo, Método do 


\section{ESTRATÉGIAS E TÉCNICAS DE ENSINO-APRENDIZAGEM NO CURSO DE CIÊNCIAS CONTÁBEIS DA UNIVERSIDADE FEDERAL DE RONDÔNIA, CAMPUS DE PORTO VELHO: PERCEPÇÃO DOS GRADUANDOS \\ DOI: http://dx.doi.org/10.5007/1983-4535.2018v11n4p167}

caso/estudo de caso, Aula pratica e de Laboratório e Aprendizagem experimental/ Estágio. Por outro lado, o resultado indica que as razões que os alunos consideraram para a escolha das estratégias mais eficazes são as que facilitam o aprendizado, e aproxima teoria da prática.

O trabalho evidenciou ainda que a desatenção dos alunos está associada com o método utilizado pelo professor, pois a didática é um dos elementos que influenciam no processo de ensino aprendizagem no qual o professor deve estar preparado para o tipo de aluno, de cultura que vai encontrar, e aplicar dinâmicas, pois as estratégias e técnicas utilizadas no ensino são instrumentos muito importantes para o desenvolvimento do ensino na educação contábil, porém o professor e aluno serão sempre os responsáveis pelo "resultado final" da aprendizagem. Espera-se que este trabalho contribua para que professores e gestores educacionais conheçam as estratégias ministradas e aquelas que oferecem maior eficácia no ensino da educação contábil, assim, esses possam analisar e planejar as estratégias de ensino compatíveis com os objetivos educacionais propostos para as disciplinas específicas da área. Sugere-se, para futuras pesquisas, a expansão da amostra envolvendo um maior número de instituições de ensino públicas e particulares que oferecem o curso de Ciências Contábeis com o propósito de investigar, por meio de entrevistas em profundidade, os motivos da escolha das estratégias de ensino aplicadas na educação contábil.

\section{REFERÊNCIAS}

ANASTASIOU, L. G. C.; ALVES, L. P. Processos de Ensinagem na universidade: pressupostos para as estratégias de trabalho em aula. 3. ed. Joinville: UNIVILLE, 2004.

BOYCE, G. Critical accounting education: teaching and learning outside the circle. Critical Perspectives on Accounting, v. 15, n. 4-5, p. 565-586, 2004.

BORDENAVE, J. D.; PEREIRA, A. M. Estratégias de ensino-aprendizagem. 23. ed. Petrópolis: Vozes, 2002

CITTADIN, A.; LAESKER, R. O perfil dos docentes do curso de ciências contábeis da Unesc e suas estratégias metodológicas. 2010. Seminário de ciências sociais aplicadas. Disponível em:http://periodicos.unesc.net/seminariocsa/article/view/1416/1343. Acesso em: 11 jul. 2016.

COSTA, S. A. da. PFEUTI, M. de Las M. CASA NOVA, Silvia Pereira de Castro. As estratégias de ensino-aprendizagem utilizadas pelos docentes e sua relação com o envolvimento dos alunos. Revista Evidenciação Contábil \& Finanças, v. 2, n. 1, p. 59-74, jan./abr. 2014. 


\section{ESTRATÉGIAS E TÉCNICAS DE ENSINO-APRENDIZAGEM NO CURSO DE CIÊNCIAS CONTÁBEIS DA UNIVERSIDADE FEDERAL DE RONDÔNIA, CAMPUS DE PORTO VELHO: PERCEPÇÃO DOS GRADUANDOS \\ DOI: http://dx.doi.org/10.5007/1983-4535.2018v11n4p167}

CRESWELL, John W. Research design: qualitative, quantitative, and mixed methods approaches. 3rd ed. Los Angeles: Sage Publications, Inc., 2009.

FERREIRA, R. S.; ALMEIDA, J. B.; ARAÚJO, W. G. Métodos de Ensino Aplicados no Curso de Ciências Contábeis: percepção de alunos da Universidade Federal do Tocantins (UFT). CIAIQ 2017, v. 1, 2017.

FONSECA, J. J. S. Metodologia da pesquisa científica. Fortaleza: UEC, 2002. Apostila

GARCIA, M. R. V.; TORRES, A. A. G. Compromisso social da universidade no Brasil: um panorama histórico. In: XVI COLOQUIO INTERNACIONAL SOBRE GESTIÓN UNIVERSITARIA EN AMÉRICA DEL SUR. Anais...Arequipa, 2016. Disponível em: https://repositorio.ufsc.br/xmlui/bitstream/handle/123456789/171046/OK\%20\%20103 00499.pdf? sequence=1\&isAllowed=y. Acesso em: 4 jul. 2017.

GIL, A. C. Métodos e técnicas de pesquisa social. 4. ed. São Paulo: Atlas. 2005. . Didática do ensino superior. São Paulo: Atlas, 2006. . Como elaborar projetos de pesquisa. 4. ed. São Paulo: Atlas, 2008.

ITOZ; C, MINEIRO, M. Ensino-Aprendizagem da Contabilidade de Custos: Componentes, Desafios e Inovação Prática. Enfoque Reflexção Contabil, v. 24, n. 2 jul./dez. 2005.

LEAL, E. A.; BORGES, M. P. de P. Estratégias de ensino aplicadas na área da contabilidade gerencial: um estudo com discentes do curso de ciências contábeis. Revista Ambiente Contábil, v. 8. n. 2, p. 1-18, jul./dez. 2016.

LIMA, I. V.; KROENKE, A.; HEIN, N. Análise de atributos relacionados ao sucesso na aprendizagem de estudantes do curso de Ciências Contábeis. 2010.Revista Gestão Contemporânea, Porto Alegre, ano 7, n. 7, p. 101-122, jan./jun. 2010.

LOPES, A. F.; AZAMBUJA, J. Q.; VEIGA, I. P. A.; CASTANHO, M. E.; SOUZA, M. L. R.; FELTRAN, R. C. L. Técnicas de ensino: por que não? São Paulo: Papirus, 2003.

LUCKESI, C. C. Filosofia da Educação. Coleção magistério $2^{\circ}$ grau. Série formação do professor. São Paulo: Cortez, 1994.

MASETTO, M. T. Competência pedagógica do professor universitário. São Paulo: Summus, 2003.

MAZZIONI, S. As estratégias utilizadas no processo de ensino-aprendizagem: concepções de alunos e professores de ciências contábeis. Revista Eletrônica de Administração e Turismo-ReAT, v. 2, n. 1, p. 93-109, 2013.

MIRANDA, G. J.; LEAL, E. A.; CASA NOVA, S. P. C. Técnicas de ensino aplicadas à contabilidade: existe uma receita? In: COIMBRA, C. L. Didática para o ensino nas áreas de administração e ciências contábeis. São Paulo: Atlas, 2012.

NGANGA, C. S. N.; FERREIRA, M. A.; NETO, E. B. M. N.; LEAL, E. A. L. Estratégias e técnicas aplicadas no ensino da contabilidade gerencial: um estudo com docentes do curso de 
ciências contábeis. In: ENCONTRO DE ENSINO E PESQUISA EM ADMINISTRAÇÃO E CONTABILIDADE, 4., 2013, Brasília. Anais... Brasília, 2013. Disponível em: http://www.anpad.org.br/admin/pdf/EnEPQ108.pdf. Acesso em 11 out. 2016.

NOSSA, V. Formação do corpo docente dos cursos de graduação em contabilidade no Brasil: uma análise crítica. Caderno de Estudos, São Paulo, FIPECAFI, nº 21, mai./ago.1999.

OLIVEIRA, L. H. Exemplo de cálculo de Ranking Médio para Likert. Notas de Aula. Metodologia Científica e Técnicas de Pesquisa em Administração. Mestrado em Administração e Desenvolvimento Organizacional. PPGA CNEC/FACECA: Varginha, 2005.

OStermanN, F.; CAVAlCANTI, C. J. de H. Teorias de Aprendizagem. Porto Alegre: Evangraf; UFRGS, 2011.

PILETTI, C. Didática geral. 23. ed. São Paulo: Ática, 2006.

RANGEL, M. Métodos de ensino para a aprendizagem e dinamização das aulas. São Paulo: Papirus, 2008.

SILVA, F. M. D.; MELO, P. A. D. Universidade e Compromisso Social: a prática da Universidade Federal de Santa Catarina. In: X COLOQUIO INTERNACIONAL SOBRE GESTIÓN UNIVERSITARIA EN AMÉRICA DEL SUR. Anais...Mar del Plata, 2010.

VIEIRA, R. M; VIEIRA, C. Estratégias de ensino/aprendizagem. Lisboa: Horizontes Pedagógicos, 2005. 